\title{
LA EMIGRACIÓN CUBANA DE CAYO HUESO (1855-1896): INDEPENDENCIA, TABACO Y REVOLUCIÓN*
}

\author{
POR \\ M. ${ }^{a}$ DOLORES GONZÁLEZ-RIPOLL NAVARRO \\ Centro de Estudios Históricos, C.S.I.C.
}

En este trabajo se estudia la comunidad de cubanos emigrados en Cayo Hueso, la mayoría trabajadores del tabaco, durante la segunda mitad del s. XIX, a través de los informes enviados por los sucesivos cónsules españoles quienes intentaron neutralizar las actividades de los independentistas mediante el espionaje y una política de acercamiento.

La proximidad de Cuba a la península de Florida ha facilitado la comunicación entre ambos territorios desde los primeros tiempos de la conquista española hasta la actualidad. En el siglo XVIII, Florida constituía una barrera contra la expansión de las Trece colonias inglesas y, como tantas tierras del Caribe, fue cedida (1763) y recuperada (1783) al compás de las guerras y los tratados de paz entre España e Inglaterra. A lo largo de esa centuria se produjeron migraciones de cierta magnitud hacia las entonces "Floridas" - la franja oriental y la occidental - que dejaron de pertenecer a España en 1819 para integrarse a la joven república estadounidense.

Consumadas las independencias de los territorios americanos en la década de los años veinte, la permanencia de Cuba y Puerto Rico como colonias de España hasta finales del siglo provocó un incesante ir y venir de antillanos separatistas por diversas partes del mundo en busca de apoyo y solidaridad con su lucha o como mero refugio en épocas convulsas. Con el inicio en 1868 de la larga guerra

* Trabajo realizado dentro del Proyecto de Investigación PB96-0868 (DGES). 
de los Diez años en Cuba, los consecuentes conflictos sociales y económicos en la isla y las llamadas a filas por parte de las autoridades españolas, dispararon la salida de cubanos; los más pudientes se instalaron en Europa, preferentemente París, mientras otros acudieron a la cercana república erigida en modelo de libertad y democracia, instalándose en ciudades como Nueva York, Nueva Orleans, Tampa y hasta en el pequeño islote de Cayo Hueso - bautizado Key West por los anglosajones- donde ya en 1831 aparecieron los primeros torcedores de tabaco provenientes de Cuba, dada la semejanza del clima del cayo con las vegas cubanas ${ }^{1}$.

Todos estos enclaves constituyeron reductos de independentistas comprometidos en mayor o menor medida con el ideal político de segregación de España; fueron miles los antillanos que se enfrentaron a la tarea cotidiana de sobrevivir en tierra extraña y que lucharon desde la distancia por mantener encendida la llama de la revolución, agrupaciones humanas a las que, obviamente, no fueron ajenas las discusiones, luchas intestinas e insolidaridad entre sus integrantes que, en ocasiones, socavaron la necesaria unión de todos, restando fuerza al movimiento y convirtiendo la inoperancia en su única virtud.

La historiografía sobre la emigración y el exilio antillano ha centrado su interés en la figura de José Martí y en la forja desde Nueva York del movimiento político-revolucionario que reinició la guerra de independencia en 1895; sin embargo, existen otras figuras a tener en cuenta en este proceso - algunos puertorriqueños como Betances y Hostos, los luchadores en la manigua- y, sobre todo, las variadas experiencias cotidianas de la masa emigrada nada ajena a las luchas obreras y a la emergencia del socialismo y del anarquismo, en las que los principios sociales se mezclaron con los políticos inherentes a su lucha patriótica. Ya para los contemporáneos "cronistas" de la lucha independentista entre los emigrados, el pequeño enclave de Cayo Hueso constituía un ejemplo de coherencia y

1 Sobre la emigración antillana véase Paul Estrade, La colonia cubana de París 1895-1898, La Habana, Ed. Ciencias Sociales, 1984; Rolando ÁlvAREZ EsTÉvEZ, La emigración cubana en Estados Unidos, 1868-1878, La Habana, Ed. Ciencias Sociales, 1986; Carlos M. RAMA, La independencia de las Antillas y Ramón E. Betances, San Juan de Puerto Rico, Instituto de Cultura Puertorriqueña, 1980; José ISERN, Pioneros cubanos en USA, 1575-1898, N.W., Cenit Printing, 1971. Sobre la emigración en Cayo Hueso especificamente, véase Gerardo Castellanos García, Motivos de Cayo Hueso (Contribución a la historia de las emigraciones revolucionarias cubanas en EEUU), La Habana, UCAR, 1935. 
rectitud porque quienes lo integraban, en su mayoría humildes trabajadores del tabaco, se mantuvieron fieles al ideal independentista sin que el anexionismo encontrara eco entre ellos (no así las propuestas autonomistas que sí atrajeron a algunos como se verá).

Para las autoridades españolas era, pues, fundamental vigilar los movimientos de tanto elemento contrario al régimen colonial en lugares tan cercanos a Cuba, dado que desde Cayo Hueso se intentaban reiteradamente expediciones a la isla para apoyar a los insurgentes con todo tipo de recursos humanos y materiales. Las tareas de control y vigilancia (espionaje) fueron encomendadas a los cónsules españoles que en lugares como Cayo Hueso, vivían aisladamente, sin relación con los cubanos y con pocos aliados entre las autoridades estadounidenses, lo que teñía el cargo de peligro y mortificación ${ }^{2}$.

En este trabajo van a estudiarse la comunidad de cubanos emigrados en Cayo Hueso durante la segunda mitad del s. XIX y sus actividades patrióticas y laborales ligadas a la industria tabaquera a través de los informes enviados por los sucesivos cónsules de Cayo Hueso a sus colegas de Washington y a los capitanes generales de Cuba, comunicaciones que eran, finalmente, despachadas al ministerio español ${ }^{3}$.

\section{CAYo HuESO, RUEDA MOTORA DE LA REVOLUCIÓN}

El puertorriqueño Eugenio $\mathrm{M}^{\mathrm{a}}$ de Hostos fue uno de tantos antillanos que soñó con la independencia de Cuba y Puerto Rico y, como muchos de ellos, residió la mayor parte de su vida fuera de su tierra natal, coincidiendo con otros emigrados en París, Puerto Plata, Nueva York, Caracas, etc. Singular fue el carácter de su lucha reivindicativa del hombre total, independiente y culto a través de la sociología, la pedagogía y el derecho. Amigo de Francisco Vicente Aguilera y de Máximo Gómez, Hostos criticó duramente el proceder de la mayoría de los núcleos de emigrados, su carencia de ideas y la falta de coordinación, en suma "el olvido de sí mismos, que es por

2 Gerardo Castellanos García, Misión a Cuba. Cayo Hueso y Martí, La Habana, Impr. Alfa, 1944, p. 86.

3 La documentación está constituida por dos legajos fechados de 1842 a 1896 custodiados en el Archivo del Ministerio de Asuntos Exteriores de Madrid, en adelante AMAE. 
donde empiezan y concluyen las revoluciones, que es el arma con que se asegura la victoria", en palabras suyas ${ }^{4}$. Solamente salvaba a una porción de cubanos refugiados en Cayo Hueso, gentes de modesta condición y los únicos que, en su opinión, conservaban el sentido del deber y el de una cubanía inmune a intoxicaciones anexionistas porque "adquieren allí lo que no tuvieron ni en otras emigraciones ni en su patria (...) No en la emigración de Nueva York, ni en la de Nueva Orleans, ni en la de París, ni en la de Puerto Plata, porque motivos varios han desligado en vez de unir a los cubanos"5.

José Martí también admiró esta emigración que tuvo oportunidad de conocer directamente en un viaje en 1891 y a la que consideró germen de la futura República. Gerardo Castellanos, hijo del que fuera comisionado de José Martí en Cuba entre 1892 y 1894 Gerardo Castellanos Llopart, nació en Cayo Hueso, peñón al que juzgaba "posesión moral legitimamente integradora de nuestra Isla" y refugio preferido de la emigración porque "jamás en sitio alguno, antes, ni después, un conglomerado de cubanos ha vivido en tanta coordinación de ideales y trabajo"6. Más recientemente Rolando Álvarez en un estudio sobre la emigración cubana en Estados Unidos durante la guerra de los Diez Años, señala Cayo Hueso como el "rincón más combativo" y además "forja de cientos de cubanos en la lucha por la independencia y la conciencia proletaria"7.

Realmente sorprende tanto la actividad industrial centrada en la producción y exportación de tabaco que floreció en Cayo Hueso, como la extraordinaria fuerza del movimiento de independencia entre los obreros de las fábricas y talleres; todo ello en un exiguo territorio, una "berruga geográfica" en palabras de Gerardo Castellanos, sin ningún atractivo en $1844^{8}$ y cuyos pobladores, anglosajones denominados "concos", se dedicaban a la extracción de sal marina y

\footnotetext{
4 Eugenio $\mathrm{M}^{\mathrm{a}}$ DE Hostos, Obras Completas, en Temas cubanos, vol. IX, La Habana, Ed. Comercial, 1939, p. 127.

5 Ibidem, "Los de Cayo Hueso", Nueva York, 31 octubre de 1874, p. 251

6 Gerardo Castellanos García, Raíces del 10 de octubre de 1868. Aguilera y Céspedes, La Habana, Impr. El Siglo, 1937, p. 150.

7 Rolando ÁlVAREZ ESTÉVEZ, [1].

8 "It is a sandy waste with some scrub timber upon it and in the town a scattering of plantation and banana trees, giving it a tropical appearance. There are several comodious warehouses here in which goods from wrecked vessels are stored away. In one of them was a room used as a Theatre", W. STANLEY HOOLE, Florida territory in 1844. The Diary of master Edward Clifford Anderson, Alabama, The University of Alabama Press, 1977, pp. 28-29.
} 
esponjas y al salvamento de vidas y propiedades de los navíos naufragados (actividad especuladora llevada a cabo por los denominados "raqueros" que constantemente cruzaban los cayos de Florida en sus goletas).

En cuanto a su número, con anterioridad a 1868 y a la masiva llegada de cubanos, la población del cayo ascendería a poco más de 3.000 habitantes $^{9}$, cantidad que iría ascendiendo paulatinamente hasta finales del siglo a pesar de los regresos de muchos trabajadores a Cuba en ciertas coyunturas políticas (paz del Zanjón, 1878) o económicas (huelgas en las décadas de los ochenta y noventa) ${ }^{10}$.

La imagen de Cayo Hueso varió notablemente a lo largo de esos años. De constituir un islote "separado del mundo entero" como señalaba en 1856 el cónsul español José $\mathrm{M}^{\mathrm{a}}$ Salas y Quiroga ${ }^{11}$, pasó a tener una rica actividad industrial, financiera, social y cultural "¿Hemos de decir ahora lo que era este Cayo Hueso antes de la emigración? No lo creemos necesario. Basta a nuestro propósito significar (...) que los cubanos con su constancia, su inteligencia y laboriosidad, de un ávido peñón en medio de los mares han hecho una ciudad comercial; la más importante del estado de Florida", publicaba un diario vespertino cayohuesero ${ }^{12}$. Esta actividad quedaba patente en las páginas de los numerosos periódicos editados en el cayo que incluían anuncios publicitarios de cafés, tiendas de ropa confeccionada, tejidos, todo tipo de utensilios de importación, materiales de construcción, hoteles, colegios y academias, traductores, pan al estilo cubano, teatros, y, como no, puntos de venta de tabaco; sin olvidar el intercambio de productos de contrabando proveniente de

\footnotetext{
9 A principios de 1855 , un informe del cónsul español José $\mathbf{M}^{\mathrm{a}}$ Salas y Quiroga, señalaba que "la población de la ciudad según el último censo [no cita la fecha de ese último censo] es de 2.803 almas de donde hay que deducir 500 esclavos y 200 personas de color libres", 6 de enero de 1855, AMAE, Correspondencia Consular, H 1867. José ISERN [1], p. 109, señalaba para 1852: 3. 000 habitantes, 650 casas, 26 tiendas, 10 almacenes, 11 muelles y 4 iglesias.

10 En 1890 habría en Cayo Hueso de un total de 18.000 habitantes 12.000 obreros tabaqueros que trabajaban en 193 manufacturas. Gerardo CASTELLANOS GARCíA, [1], p. 185.

11 La precariedad financiera, el aislamiento y la lejanía de sus familias y de España constituye un queja continua entre los cónsules españoles. José $M^{a}$ Salas y Quiroga, 25 de noviembre de 1856. AMAE, Correspondencia consular, H-1867.

12 AMAE, Correspondencia consular, H-1868. "Cuestión palpitante", El Cubano, Cayo Hueso, año $\mathrm{I}, \mathrm{n}^{\circ} 111,30$ diciembre de 1887.
} 
La Habana como manteca, mantequilla, pólvora, zapatos, vestidos y opio $^{13}$.

Tal afluencia de mercaderías era posible por la estratégica situación de Cayo Hueso en las rutas de los navíos desde el norte hacia los puertos del seno mexicano, incluidos los barcos que se detenían para aprovisionarse de carbón cuando en La Habana se declaraba la fiebre amarilla. Por tanto, a fin de evitar el cierre del puerto, las autoridades estadounidenses del cayo no estaban interesadas en que se hiciera la declaración sanitaria de los barcos que atracaban en su puerto, lo que molestaba al cónsul español Hipólito de Iriarte quien, en 1858 , aconsejaba revisar las cargas y pasajeros de cualquier navío que hubiera tocado en Cayo Hueso ya que "la mayoría de los habitantes de esta población (...) han procurado mantener la creencia de que Cayo Hueso era un punto muy sano y que la fiebre amarilla no era aquí contagiosa"14. Posteriormente, otro cónsul español señalaba sobre el estado sanitario del cayo que "por su proximidad y comunicación diaria con La Habana se padece la fiebre amarilla en las mismas épocas que en dicha ciudad y Puerto, pero además todo el año hay constantemente calenturas cotidianas intermitentes y tifoideas, con otras varias enfermedades producidas por el excesivo calor, mala calidad de los alimentos y de las aguas y por el abuso que hacen estos habitantes y hombres de mar de las bebidas fuertes y espirituosas"15.

Al margen de los problemas sanitarios y de orden público (incendios muy frecuentes, por ejemplo) causados, entre otros factores, por las elevadas temperaturas, la similitud del clima entre Cayo Hueso y las zonas vegueras de Cuba (grado de humedad) benefició la producción de tabaco y posibilitó que llegaran unos 50 tabaqueros en fecha tan temprana como 1831 para trabajar en la primera fábrica de tabacos del cayo propiedad de William $\mathrm{H}$. Wall que fue destruida por el fuego en 1859 forzando a los empleados a buscar acomodo en otra parte. Estos emigrados pertenecían, pues, a un sector concienciado de su situación y de la opresión política ejercida por la metrópoli y, aunque constituyeron un exiguo número hasta el estallido de

\footnotetext{
13 AMAE, Correspondencia consular, H-1867. Información del cónsul español Augusto Bermúdez, 30 de julio de 1883.

14 AMAE, Correspondencia consular, H-1867. "Estado sanitario del Cayo", 15 de diciembre de 1858 .

15 AMAE, Correspondencia consular, H-1867. Mariano Álvarez, 27 octubre de 1859.
}

R. I., 1998, n. 212 
la guerra ocho años más tarde, se mantenían informados sobre los planes urdidos en Nueva Orleans para acabar con el poder español en Cuba, desde donde se enviaban consignas y periódicos adeptos a la causa separatista tanto a la propia isla de Cuba como a Cayo Hueso. Para los cónsules españoles, que en 1860 recibían la orden de enviar cada año una copia de los registros de españoles matriculados en Cayo Hueso así como "una nota lo más exacta posible de los emigrados por causas políticas o de cualquier otra naturaleza"16 estos "refugiados o los que se quieren dar importancia de refugiados o mártires políticos" soñaban con conspiraciones "y otras declamaciones exageradas a que se presta tan facilmente la imaginación ardiente de los Americanos del Sur"17.

Finalmente, el levantamiento en octubre de 1868 daría inicio a una larga guerra en Cuba en la que, tanto la propia ruina económica como la llamada general a filas y la temible actuación de los regimientos de Voluntarios contra los partidarios de la revolución, provocaron la huida masiva de unas 20.000 personas en los dos primeros años de lucha. En su mayoría eran trabajadores del ramo del tabaco: torcedores, despalilladores, escogedores, capataces, fileteadores, aprendices, etc., "sobre catorce mil operarios de cigarros puros y de papel" que se establecieron en Estados Unidos, con preferencia en Cayo Hueso, Nueva Orleans y Nueva York ${ }^{18}$. En 1869, Cayo Hueso contaba ya con el primer club revolucionario de emigrados cubanos con el nombre de Asociación Patriótica de Cayo Hueso, organizada y presidida por José Dolores Poyo y Juan $\mathrm{M}^{\mathrm{a}}$ Reyes como secretario, se fundaron logias masónicas, una asociación de jóvenes emigrados revolucionarios "La Juvenil", una Asociación patriótica del Sur -establecida por mandato de la agencia central de la República cubana en Nueva York- y, en 1871, se fundaba la Sociedad el Ateneo después convertida en el club San Carlos, centro de reunión y propaganda de los cubanos independentistas quienes pu-

16 AMAE, Correspondencia consular, H-1867. Vicente Cubells, 24 de marzo de 1860. 1858

17 AMAE, Correspondencia consular, H-1867. Hipólito de Iriarte, 24 de diciembre de

18 Véase Joan CASANOVAS Codina, "El asociacionismo burgués y proletario en Cuba de los años 1870 a inicios de los 1880", Cuba, algunos problemas de su historia, Iberoamericana Pragensia - Supplementum 7/1995, pp. 97-115. Casanovas recoge el número de operarios emigrados del Gremio de la Industria del Tabaco, Exposición al intendente de la Real Hacienda de La Habana, La Habana, 1872. 
blicaban periódicos para informar y alentar a los suyos como $\mathrm{El} R e$ publicano dirigido por Juan $\mathrm{M}^{\mathrm{a}}$ Reyes. Los litigios en la prensa de unos y otros partidarios se extendían al territorio cubano como quedó patente en el caso de la muerte del español Gonzalo Castañón, director del periódico "La Voz de Cuba" de La Habana, ocurrida el 31 de enero de 1870 en un hotel de Cayo Hueso adonde había ido para batirse en duelo con Juan $\mathrm{M}^{\mathrm{a}}$ Reyes después de una serie de afrentas intercambiadas sobre el papel ${ }^{19}$.

Este caso provocó la indignación de los españoles y la detención de numerosos cubanos por parte de las autoridades americanas; algunos residentes en Cayo Hueso solicitaron permiso para regresar a Cuba y en febrero de 1870 embarcaban 21 personas en el vapor "Churruca" según el informe del cónsul español Enrique Ruiz ${ }^{20}$. Además, como una cadena de causas y consecuencias para la historia de Cayo Hueso, el caso Castañón afectó a la credibilidad de Vicente Martínez Ibor, un exitoso productor de tabaco recién instalado en el cayo, acusado por los agentes españoles de permitir lecturas contra España en su fábrica y por los cubanos de plegarse a las consignas de los voluntarios obligándole a cerrar temporalmente su fábrica de Cayo Hueso ${ }^{21}$. Como último eslabón de la cadena, la profanación de la tumba de Castañón fue el motivo del fusilamiento de los estudiantes de medicina en noviembre de 1871 en La Habana 22.

La fábrica de Martínez Ibor, donde era lector José Dolores Poyo más tarde director del periódico El Yara, fue una de las visitadas en 1874 por Francisco Vicente Aguilera, vicepresidente de la República en armas, en su viaje para recolectar fondos entre las comunidades cubanas de Estados Unidos. En Cayo Hueso, donde "cubanos eran el

19 Véase Juan Ignacio DE ARMAS y CÉSPEDES, "Combate de Russell House o Muerte de Castañón en Key West por un cubano", Nueva Providence, 1870, 12 pp.

20 AMAE, Correspondencia consular, H-1867. Cayo Hueso, 4 de febrero de 1870.

21 L. Glenn Westfall, Don Vicente Martinez Ibor, the man and his empire, New York \& London, Garland Publishing, INC, 1987. Martínez Ibor (o Ybor en territorio norteamericano) interesado en minimizar los conflictos laborales trasladó sus fábricas de La Habana a Cayo Hueso, Nueva York, etc. hasta conseguir su propia comunidad industrial en Ibor City.

22 José Rivero Muñiz tiene una versión distinta de la marcha de Martínez Ibor a Cayo Hueso que sería posterior a la expresada. Sostiene Rivero Muñiz que con ocasión de los fusilamientos de los estudiantes los Voluntarios saquearían la casa de D. Vicente Martínez Ibor lo que le llevaría a abandonar Cuba con ayuda del conde de Galarza e instalarse en Cayo Hueso, José Rivero MuÑz, Tabaco, su historia en Cuba, La Habana, Instituto de Historia, tomo II, p. 318 , nota 7.

R. I., 1998, n. $^{\circ} 212$ 
tabaquero, el lector de tabaquería, el vendedor de café, el barbero, el viandero..." ${ }^{23}$, Aguilera visitó también el taller de Samuel Wolf y el de Artesanos Cubanos, resaltando el entusiasmo y patriotismo de los obreros en sus aportaciones a la causa. Entre la información enviada por Aguilera a Miguel Aldama se encuentra el listado del dinero recolectado en Cayo Hueso y otras ciudades de Estados Unidos con el saldo siguiente ${ }^{24}$ :

Filadelfia (Asociación Patriótica):

800 pesos

Algunos ciudadanos: ............................. 23 pesos

Baltimore: ........................................... 266 pesos

Nueva Orleans en efectivo: .................... 231,50 pesos

En ofertas en dinero: .............................. 184 pesos

Key West: .................................................5.268,40 pesos

Aguilera no escatimó elogios hacia los emigrados de todas las ciudades en general "de excelente índole, toda trabajadora y amiga del orden" y de Cayo Hueso en particular: "de los propios labios del Gobernador Juez de Marina y Administrador de la Aduana de Key West oí hacer los más grandes elogios de la emigración, por su amor al trabajo, al orden y por su respeto a las leyes del país (...) a pesar del grande aumento que con esta emigración había tenido el pueblo"25, unos 3.000 empleados en 29 fábricas en $1876^{26}$. Gerardo Castellanos abundó en esta imagen de una emigración unida al describir una suerte de edén tropical donde la relación entre propietarios y obreros era buena, donde "el fabricante se casaba con despalilladora y el tabaquero con la hija del burgués" y donde el común interés político minimizaba las tensiones laborales "puesto que un paro, una huelga afectaba los destinos y propósitos del Partido Revolucionario"27. Sin embargo, las huelgas por tratar de hacer más justas y saludables las condiciones de trabajo en los talleres fueron frecuentes

\footnotetext{
23 R. Álvarez EstÉvez, [1] p. 41

24 Carta de Francisco Vicente Aguilera a Miguel Aldama. Nueva York, 28 de mayo de 1874. En Francisco V. Aguilera, Epistolario, La Habana, Ed. Ciencias Sociales, 1974, p. 140

25 Ibidem, p. 145

26 Según L. GlenN WestFall [21] del listado de la Oficina de la Reveneu de Florida, p. 35

27 G. Castellanos y García, [2] p. 43
} 
ya que, aunque los propietarios ayudaban economicamente en la lucha por la independencia, no dejaron de explotar a los obreros ${ }^{28}$.

La precaria situación de estos trabajadores, en ocasiones represaliados por sus patronos después de una huelga, unida a la esperanza nunca perdida de regresar a Cuba, llevó a muchos (una tercera parte de los trabajadores) a dejar el cayo al término de la guerra, merced al indulto concedido por el Gobernador General. Los que permanecieron en Cayo Hueso manifestaron su rechazo ante la firma del acuerdo en una resolución tomada en el club San Carlos ${ }^{29}$ destinada a continuar la lucha.

\section{LAS TAREAS DEL CONSULADO ESPAÑOL: ESPIAR Y DIVIDIR}

En 1880 el cónsul español señalaba respecto a esta población cubana "cuyo número nunca baja de tres mil almas y en ocasiones llega a siete mil compuesta en su mayor parte de gente adicta a la causa de la insurrección y de facinerosos que salen de Cuba huyendo de la justicia", que para descubrir lo que se fraguaba entre ellos era preciso "penetrar las interioridades de esa sociedad y ciertamente no será a mí, considerado como su enemigo natural, a quien dejarán conocer lo que les importa ocultar"30. En adelante, los cónsules españoles tratarían de conocer "el espíritu de la población" de diversos modos, desde la contratación de espías, a otras argucias para pulsar indirectamente la opinión de los cubanos y conocer sus actividades, centradas en organizar expediciones y traficar con armas destinadas a $\mathrm{Cu}$ $\mathrm{ba}^{31}$. Además, con cada convocatoria de elecciones presidenciales en Estados Unidos, demócratas y republicanos se disputaban el voto de

\footnotetext{
28 Respecto a las luchas obreras, véase Instituto de $\mathrm{H}^{\mathrm{a}}$ del Movimiento comunista, Historia del movimiento obrero cubano, 1865-1958, 2 vols., La Habana, Ed. Política, 1985 y Jean STUBBS, Tabaco en la periferia. El complejo agro-industrial cubano y su movimiento obrero 1860-1959, La Habana, Ed. Ciencias Sociales, 1989.

29 Cayo Hueso, 11 de marzo de 1878. Resolución firmada por el comité: Carlos Manuel de Céspedes, José Dolores Poyo y Martín Herrera. R. ÁlvAREZ EsTÉvEZ, [1] pp. 155156.

30 AMAE, Correspondencia consular, H-1867. Cayo Hueso, 28 de noviembre de 1880.

31 Por ejemplo, el cónsul Augusto Bermúdez sospechaba de los viajes de un buque en cuyo cargamento había latas de tomate que contenían pólvora y que habría desembarcado armas en algún lugar de la costa de Cuba. AMAE, Correspondencia consular, H-1867. En carta al Capitán General de Cuba, 7 de diciembre de 1883.
}

R. I., 1998, n. ${ }^{\circ} 212$ 
los cubanos residentes en el cayo, circunstancia denunciada sin cesar por el cónsul español que recelaba del trato de favor que las autoridades norteamericanas les otorgaban. "El tiempo dirá - escribía Augusto Bermúdez al ministro de Estado en vísperas de su vuelta a España-si tenía o no razón el que suscribe en preveer que Cayo Hueso está llamado a ser esta vez foco principal de los bandoleros"32.

Tras el Zanjón y el final de la guerra Chiquita, Cayo Hueso recibió un nuevo contingente de cubanos, entre los que llegó Fernando Figueredo en 1881, incansable propagandista de la independencia ${ }^{33}$, editor del periódico La Voz de Hatuey, designado inspector de la aduana de Cayo Hueso y cuya casa era muy visitada, incluso por comisionados del partido autonomista. Figueredo perteneció junto a otros cubanos como José Dolores Poyo al Centro Nihilista Ubiquitario Cubano que publicaba un periódico El Ubiquitario donde se animaba a la causa separatista y se alertaba en contra de los trabajadores partidarios de España en la idea de que "el español separatista es nuestro hermano pero el que no lo sea ese es y será siempre nuestro enemigo" 34 .

La mayor concentración de cubanos en Cayo Hueso y su esmerada organización en la década de 1880 preocupó seriamente a las autoridades españolas. En 1885, la prensa estadounidense calculaba en 5.500 el número de empleados en las fábricas de tabaco ${ }^{35}$ a quienes el vicecónsul español José W. Fromsky calificaba de "pobre gente que se ve obligada a vivir del mezquino jornal que gana en las fábricas de tabacos que allí tienen establecidas varios ricos propietarios de Cuba"36. El informe de Fromsky, redactado durante una estancia en Madrid, contenía otras observaciones sobre Cayo Hueso que denotaban una visión en parte sospechosa por optimista y que contrastaba con las opiniones de otros cónsules, alguno de los cuales no había ocultado su recelo por la aparente simpatía de Fromsky

32 AMAE, Correspondencia consular, H-1867. Cayo Hueso, 31 de diciembre de 1883.

33 Entre 1882 y 1885 pronunció una serie de conferencias sobre la guerra de los Diez años en el club patriótico "Hijas de la Libertad" de Cayo Hueso que fueron publicadas en el centenario de 1868: Fernando FIGUEREDo SOCARRÁs, La Revolución de Yara 1868-1878, La Habana, Instituto del Libro, 1968.

34 AMAE, Correspondencia consular, H-1867. Artículo "Alerta", El Ubiquitario, Key West, año I, $\mathrm{n}^{\circ} 1,12$ de noviembre de 1883 . [22] p. 39

35 Tobacco Leaf, Nueva York, 7 de febrero de 1885. Citado en L. GlenN WestFall

36 AMAE, Correspondencia consular, H-1868. Madrid, 30 de abril de 1884.

R. I., 1998, n. $^{\circ} 212$ 
hacia los emigrados cubanos. Fromsky suavizaba la imagen de Cayo Hueso como lugar de paso de expediciones de armas y hombres a Cuba porque lo accidentado de la costa y los numerosos bancos de coral dificultaban el acceso al cayo para añadir que, en caso de llevarse a cabo un desembarco, "reinando buena amistad entre las autoridades americanas y las nuestras, nos mandan aviso". Sin embargo, en ocasiones, la presencia en el cayo de ciertos cabecillas de la revolución cuya entrada no se tenía registrada se debía a que el intercambio de hombres se realizaba en el mar desde barcos que los traían de Cuba a barquichuelas de pescadores. Señalaba también Fromsky la costumbre de encender hogueras en Cárdenas y Matanzas para guiar las posibles expediciones "filibusteras" a la isla que, en su opinión, constaban generalmente de armas y no de hombres ya que "Terranova es un punto más acorde para esto".

Los intentos de las sucesivas autoridades españolas de controlar los movimientos de los emigrados continuaban encaminándose a la creación de una red de espías infiltrados en la comunidad cubana de Cayo Hueso, actividad que dió finalmente sus frutos. El cónsul $\mathrm{Au}-$ gusto Bermúdez contaba con un "detective" con quien se reunía a altas horas de la noche en la casa del colector interino de la Aduana (Mr. Hubbs), único funcionario estadounidense fiel a la causa española. Gracias a ambos, llegaba a manos del cónsul la correspondencia de muchos cubanos, incluidas claves de mensajes cifrados, cuyo contenido comunicaba al gobernador de la Isla: "hace mucho que desconfíaba de Julio Sanguilí y (...) según se desprende de la citada carta, el lazo de unión entre estos dinamiteros y autonomistas que pretenden herirnos a traición (...) no tardará en suceder"37. Bermúdez pudo saber que "dos nihilistas cubanos" planeaban asesinarle, información que le pasó un espía a sueldo y un cubano revolucionario que, sin embargo, reprobaba tan extrema medida.

En 1885 tuvo lugar la visita de Máximo Gómez a Cayo Hueso donde instó a la disolución de la Sociedad de Dinamiteros, logró reunir entre los emigrados cubanos más de 8.000 pesos y les dedicó una expresiva despedida: "Muchachos, hasta que llegue el momento", frase que el cónsul español refería rapidamente a las autoridades

37 AMAE, Correspondencia consular, H-1868. Cayo Hueso, 8 de junio de 1884, "Confidencial y muy reservada".

R. I., $1998, \mathrm{n}^{\circ} 212$ 
españolas $^{38}$. A la marcha de Máximo Gómez, después de manifestaciones y reuniones frecuentes, sucedió un período de calma entre los emigrados, entendido por el cónsul como un cambio de táctica, en el que seguiría fomentándose la lectura en los talleres de tabaco "de todo aquello que mantenga vivo el recuerdo de las atrocidades cometidas en Cuba por el gobierno español"39, momento que, sin embargo, precedió a la huelga de los tabaqueros en agosto que llevó al cierre de las grandes fábricas y hasta de pequeños establecimientos obligando a cientos de trabajadores a regresar a Cuba o a marcharse a otras ciudades del estado como Jacksonville. La honda división de intereses entre fabricantes y operarios que había conducido a la huelga tuvo, asimismo, nefastas consecuencias respecto al ideal político; situación que se agravó tras el devastador incendio declarado en un café al lado del club San Carlos quedando a salvo el consulado español y unicamente las sedes de los periódicos cubanos El Yara y La Propaganda. El fuego destruyó casi todas las fábricas de tabaco y dejó sin trabajo a más de tres mil operarios. El gobierno de Cuba decidió seguir una política de atracción y ofreció transporte gratuito a quienes quisieran volver a la Isla. A pesar de la campaña de rechazo por parte de los dirigentes cubanos, que incluso tomaban nota a pie de muelle de los embarcados, la operación fue un éxito y en sólo dos días fueron despachadas 500 personas. Esto provocó intensos rumores de que el incendio había sido causado por el gobierno de España para destruir el foco revolucionario y la industria tabaquera de Cayo Hueso, lo que era negado desde el consulado que, sin embargo, mostraba la satisfacción de haber logrado restar fuerzas a los enemigos con una muestra de generosidad interesada ${ }^{40}$.

La prensa española de Cuba reflejó con complacencia la dramática situación del cayo después del incendio reproduciendo artículos como el publicado en El Yara "¡Despierta Cayo Hueso!, cuyo vehemente título intentaba no dar la razón a los que veían "un principio de disolución entre los emigrados cubanos" y se asombraban

\footnotetext{
38 AMAE, Correspondencia consular, H-1868. Francisco Fernández Iguzquiza al Capitán General de Cuba y al Ministro de Estado. Cayo Hueso, 2 de marzo de 1885.

39 AMAE, Correspondencia consular, H-1868. "Lectura en los talleres", El Yara, 11 de abril de 1885 , año VIII, $\mathrm{n}^{\circ} 22$.

40 José RIVERo MUÑIZ señala que los tabaqueros solicitaron la ayuda al gobierno español que accedió por interés al traslado de numerosas familias a La Habana dando lugar al fomento de un barrio que desde entonces empezó a llamarse Cayo Hueso. [22] p. 316.
} 
de su "actual mansedumbre" en comparación con otras épocas ${ }^{41}$. Las autoridades españolas quisieron controlar otros frentes como Tampa, lugar que recibía un buen número de trabajadores, con el envío de operarios afines a la causa española que eran mirados con recelo por los cubanos: "Emilio Garcia había pronunciado un furioso discurso en contra de los peninsulares y sus oyentes, animados con lo que les había dicho y con la ayuda del aguardiente que se repartió gratis en la taberna de García, salieron en tumulto disparando tiros"42.

Como señalaba el cónsul español del momento Joaquín M. Torroja, la cuestión de fondo en el seno de la emigración cubana de Cayo Hueso era el conflicto entre "patria y trabajo" que el periódico La Propaganda zanjaba proclamando la indisolubilidad de ambas causas para la lucha obrera ${ }^{43}$. Según Torroja los prohombres del "laborantismo" sostenían que la patria estaba ante todo y que como cubanos no debían permitir que los peninsulares se establecieran en Cayo Hueso o Tampa. Por el contrario, los cubanos afiliados a los Caballeros del Trabajo sostenían que la cuestión laboral se anteponía a todas las demás y que si bien ellos como cubanos eran separatistas, como obreros carecían de nacionalidad y podían mirar a los peninsulares como "hermanos obreros". Esta idea perjudicaba a los patriotas a la hora de recaudar fondos en los talleres apelando a la causa revolucionaria como única reivindicación y dificultaba el abuso de los propietarios sobre el operario ya que "en caso de reclamaciones o querer declararse en huelga no había más que sacar a relucir la patria y amenazar con la excomunión de mal cubano al que reclamase mayor precio o mejor material para su trabajo" 44 .

Aunque esta permanente lucha por derechos laborales y políticos afectaba a los componentes de la comunidad cubana, eran las autoridades españolas las que se replanteaban las condiciones de producción y comercialización del tabaco en Cayo Hueso como medio de sofocar la llama revolucionaria. A principios de 1887 Torroja des-

\footnotetext{
41 AMAE, Correspondencia consular, H-1868. En El Español. Diario político de la tarde. La Habana, miércoles 19 de mayo de $1886, \mathrm{n}^{\circ} 116$, año II.

42 AMAE, Correspondencia consular, H-1868. Joaquín M. Torroja al ministro de Estado, Cayo Hueso, 28 de noviembre de 1886.

43 AMAE, Correspondencia consular, H-1868. "Política y trabajo", La Propaganda. Cayo Hueso, 21 de noviembre, $n^{\circ} 6$, época II.

44 AMAE, Correspondencia consular, H-1868. Joaquín M. Torroja al Ministro de Estado. Cayo Hueso, 8 de noviembre de 1886 .
} 
cribía descarnadamente los sentimientos de la mayoría de los habitantes del cayo respecto a los peninsulares: "Aquí no hay razón, no hay más que odio a muerte a todo lo que es español; de nada sirve la política de atracción y no queda más que un recurso para acabar con este semillero de discordias, este refugio de criminales disfrazados de víboras, destruirlo para siempre y su destrucción depende como en otras ocasiones (...) en la legislación sobre la industria del tabaco en la isla de Cuba"45.

Pero no sólo la legislación sobre el tabaco continuó atrayendo a multitud de cubanos, sino que la justicia estadounidense convirtió el cayo en zona franca para quienes tenían problemas con la justicia española al no ser aplicado el tratado de extradición firmado entre los dos países. Reconocidos bandoleros como Carlos Agüero y Manuel García "el Rey de los campos de Cuba"46 se reunían con otros refugiados en casa de Cecilio Henríquez para planear su regreso a la isla en expediciones cuyo coste oscilaba entre 150 y 500 pesos y participaban en las celebraciones de la comunidad cubana, siendo los aniversarios del levantamiento de Yara los más señalados. Como era habitual, en octubre de 1887 cuando se cumplía el décimonoveno aniversario, los cubanos del cayo salieron a la calle en festiva manifestación de unas doscientas personas llevando la bandera americana, dos de Cuba independiente y una banda de música; la comitiva se dirigió al cementerio, puso la primera piedra en el solar del club San Carlos y por la noche se celebró una velada en la sociedad "El Progreso" donde se pronunciaron encendidos discursos revolucionarios. En opinión del cónsul español en carta a su homónimo en Washington, la manifestación no había sido muy concurrida - punto de vista repetido en cada informe - porque aparte de niños y mujeres sólo habían acudido unos cien hombres de una población que juzgaba en "6.000 almas", entre ellos "Delgado, Ruz, Segura, Blas López, Pérez, Ramón Rivero, Pequeño y demás agitadores de oficio, estando representados los bandidos por el mulato José Rodríguez (...) se notaba la falta de cubanos de posición, residentes en esta ciu-

45 AMAE, Correspondencia consular, H-1868. Joaquín M. Torroja al Ministro de Estado. Cayo Hueso, 31 de enero de 1887.

46 Manuel de PAZ, José FERnÁNDEZ y Nelson LóPEZ, El bandolerismo en Cuba, vol. I, Santa Cruz de Tenerife, Centro de la Cultura Popular Canaria, 1993, y El bandolerismo en Cuba. Presencia canaria y protesta rural, vol. II, Santa Cruz de Tenerife, Centro de la Cultura Popular Canaria, 1994. 
dad, de conocidas ideas separatistas y aún los tabaqueros estuvieron pobremente representados" 47 .

Para "fabricar entusiasmo" y levantar el espíritu un tanto decaído de "una emigración desengañada al ver que después de 19 años $\mathrm{Cu}$ ba seguía siendo española" 48 , se aprovechaban otros acontecimientos, desde el funeral del director del periódico La Propaganda que murió asesinado, a una efemérides tan señalada como la del fusilamiento de los estudiantes de medicina ${ }^{49}$. Un abatimiento que se agudizaba tanto por las disensiones internas como por los efectos de la política de atracción del gobierno español hacia ciertos prohombres de la revolución. La pugna por el modo de recolectar dinero entre Juan Fernández Ruz que había manifestado su oposición a Martí y Flor Crombet, el primero partidario de conseguirlo de cualquier manera incluso a través del bandidaje y el segundo sólo considerando legítimas las suscripciones, provocó un clima de desconfianza generalizada y de sorprendentes tomas de postura. El cónsul español refería que Carlos Baliño al recibir a Flor Crombet en el club El Progreso se declaró "abiertamente partidario de los principios y no de los hombres, llegando su radicalismo hasta el punto de mostrarse partidario de los españoles si es que éstos eran los que realizaban sus ideas en Cuba, teoría de la que protesta La Propaganda en un suelto titulado "Cubanos antes que todo"50.

Respecto a la estrategia del gobierno español de dividir la compacta colonia cubana desplegando una política de atracción de sus elementos más influyentes para convencerles de lo estéril y erróneo de su actitud, hay que señalar que, a la altura del verano de 1889 ,

\footnotetext{
47 AMAE, Correspondencia consular, H-1868. Carta del cónsul J. Torroja al cónsul español en Washington. Cayo Hueso, 11 de octubre de 1887. Un año después, Torroja dirá de la misma celebración que ha sido menos concurrida que el año anterior y menos entusiasta; la de 1890 será considerada "pobre" y también "menos concurrida que el año pasado" por el cónsul Francisco de Baguer.

48 AMAE, Correspondencia consular, H-1868. Carta del cónsul J. Torroja al capitán general de Cuba. Cayo Hueso, 30 de noviembre de 1887.

49 AMAE, Correspondencia consular, H-1868. Se celebró una velada abierta por Francisco Lamadriz y con discursos de Carlos Baliño, Pedro Someillán, Rogelio Castillo, Martín Morua Delgado, Fernando Figueredo, Manuel Sánchez, Francisco Segura, Antonio Valdés Landín y el alcalde de la ciudad Mr. Plummer. Además se leyeron composiciones y

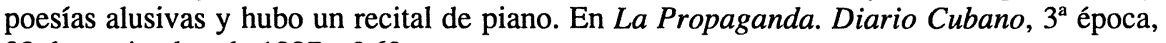
28 de noviembre de $1887, n^{\circ} 63$.

50 AMAE, Correspondencia consular, H-1868. Carta del cónsul J. Torroja al capitán general de Cuba. Cayo Hueso, 2 de marzo de 1888.
} 
había dado sus frutos: Ruz se había retirado a Barcelona, Máximo Gómez se encontraba en una hacienda en Santo Domingo y Flor Crombet se había acogido a indulto en Jamaica. Repentinamente, el 13 de agosto el director del periódico separatista El Cubano de Cayo Hueso, D. Pedro N. Pequeño, uno de los refugiados más combativos, anunciaba su dimisión y publicaba un manifiesto "Al pueblo cubano" adhiriéndose a la propuesta autonomista. El nuevo cónsul español Luis Marinas se vanagloriaba del triunfo sobre Pequeño a quien había convencido del "error grave en que estaba incurriendo decidiéndose a abandonar por completo el falso ideal de Cuba libre e independiente que no sólo profesaba, sino que también propagaba, inculcaba y robustecía en el ánimo de sus compatriotas por medio de su intransigente publicación (...) regresando a su país en donde me ha ofrecido trabajar en la medida de sus fuerzas en pro de legítimos e indiscutibles derechos de la Madre Patria y combatir todo lo que a este fin se oponga"51. La realidad se aliaba con las gestiones del cónsul Marinas, a quien se acusaba de haber españolizado el cayo facilitando el regreso de muchos tabaqueros a $\mathrm{Cuba}^{52}$ y cuya destitución era solicitada hasta por las autoridades estadounidenses. A fines de 1889 Marinas estimaba destruido el cayo como foco político separatista y como centro tabaquero, al constatarse la marcha de casi 4.000 personas hacia La Habana y Tampa; además El Yara dejó de publicarse diariamente y La Nueva Era, "órgano de la raza de color" desapareció.

La última década del siglo trajó la visita de José Martí a Cayo Hueso para establecer el Partido Revolucionario Cubano y contactar con los obreros a quienes instó a fundar clubes de apoyo ${ }^{53}$. Desde el consulado se intentó neutralizar estas actividades reclutando rompehuelgas españoles, lo que provocó la creación de La Tranca, una agrupación dedicada a impedir el desembarco de españoles en el cayo.

51 AMAE, Correspondencia consular, H-1868. Carta del cónsul Luis Marinas al capitán general de Cuba. Cayo Hueso, 13 de agosto de 1889.

52 AMAE, Correspondencia consular, H-1868. Marinas facilitó medio de transporte a 267 obreros tabaqueros que regresaron a Cuba en dos viajes. En carta al cónsul español en Washington. Cayo Hueso, 27 de noviembre de 1889.

53 Véase Joan CASANOvas CODINA, "El movimiento obrero y la política colonial española en la Cuba de finales del XIX", en Consuelo NARANJo, Miguel A. PuIG-SAMPER y Luis M. García Mora (eds.), La Nación Soñada: Cuba, Puerto Rico y Filipinas ante el 98, Madrid, Ed. Doce Calles, 1996, pp. 363-375. 
El clima de tensión llegó a su cenit durante las intermitentes huelgas de 1893 a 1895. El cónsul informaba de la deplorable situación de más de 4.000 hombres sin trabajo y resolvía, en el verano de 1893, el transporte a Cuba de muchas familias en contra de los más intransigentes con el gobierno de España. La dispersión de muchos de estos cubanos desde Cayo Hueso a otras ciudades de Florida como Martí City (Ocala) y, sobre todo Tampa, fue la consecuencia de las diferencias surgidas también entre la población cubana y la estadounidense que finalmente optó por gritar "¡Cayo Hueso libre!"54.

Con la guerra iniciada en 1895, la industria tabaquera sobrevivió a esta crítica etapa, agudizada por las medidas tomadas desde Cuba tendentes a evitar la exportación de tabaco y dejar sin materia prima a las fábricas de Florida, lo que no se consiguió. Los americanos se adelantaron a un bando de Weyler promulgado el 16 de marzo de 1896 y embarcaron grandes cantidades de tabaco en rama destinado a Cayo Hueso y Tampa ${ }^{55}$. Así pues, la "cubanización" de la península de Florida prosiguió y en la actualidad, un siglo después, se muestra más cubana que nunca.

This article studies the community of Cuban emigrates, most of them tobacco workers, in Key West (Florida) in the second half of the ninenteenth century through the reporters sent by the Spanish consuls, who tried to prevent independentist activities by means of spying and an approach policy.

\footnotetext{
54 AMAE, Correspondencia consular, H-1868. Las Novedades, Nueva York, 7 de febrero de 1894.

55 En Gerardo Castellanos [2], p. 317.
}

R.I., 1998, n. ${ }^{\circ} 212$ 